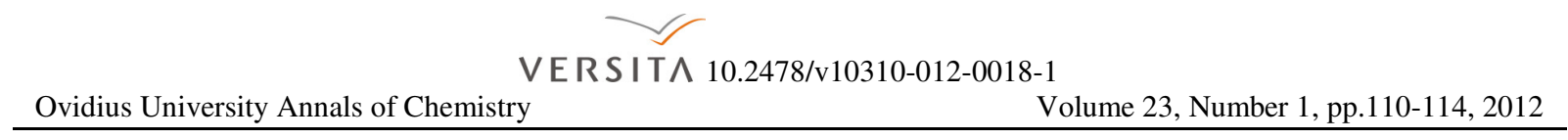

\title{
Determination of organophosphorus pesticides in baby food
}

\author{
Simona DOBRINAS*, Alina SOCEANU, Gabriela STANCIU and Adriana CULEA \\ ${ }^{a}$ Department of Chemistry, Ovidius University of Constanta, 124 Mamaia Blvd, 900527 Constanta, Romania
}

\begin{abstract}
Measurements of organophosphorus pesticides residues were conducted on four different baby food puree based on vegetable, fruit, white fish and veal, products based on cereals and biscuits packed in cardboard box using gas chromatography with thermoionic specified detector (GC-TSD). The lowest concentration of organophosphorus compounds was found for sulfotep, $0.00006 \mathrm{mg} / \mathrm{kg}$ in biscuits, while the highest concentrations were found for diazinon and fenchlorphos, with values of $0.1096 \mathrm{mg} / \mathrm{kg}$ and $0.1903 \mathrm{mg} / \mathrm{kg}$, both in the grain samples.
\end{abstract}

Keywords: organophosphorus pesticides, GC-ECD, baby food

\section{Introduction}

Reduction of children's risk from pesticides requires an understanding of the pathways by which exposure occurs. Dietary ingestion is one of the pathways by which children are exposed to pesticides. Children eat more food per body mass than adults, and their diets differ from those of adults. These diets are often rich in foods containing higher levels of pesticide residues [1].

Organophosphorus pesticides (OPPs) are used widely for agriculture, vector control and domestic purposes. Despite the apparent benefits of these uses acute these pesticide poisoning is an increasing worldwide problem. Organophosphorus pesticides are the most important cause of severe toxicity and death from acute poisoning worldwide [2].

OPPs represent one of the most important classes of cholinesterase inhibitors. OPPs irreversibility inactivate acetylcholinesterase, which is essential for nerve function in insects, humans and many animals. It degrades rapidly when exposed to sun, air and soil, but small amounts can be detected in food and drinking water.

US Environmental Protection Agency banned most organophosphorus pesticides in 2001, but they are still used in agriculture to spray vegetables and fruit and they can be absorbed through the lungs or skin or by eating food [3-4]. Baby foods should be free of pesticide residues, according to the extremely low maximum residue limits (MRLs) established by the European Community in 2006 [5]. Thus, the monitoring of pesticide residues in such high risk matrices should be accurate and reliable [6].

Pesticides have been determined in baby food by the use of a wide range of techniques such as HPLCMS/MS [7], GC-MS [8], GC-ECD [9], GC-MS-MS [10].

Very important are the evaluation and improvement of sample extraction and clean-up methods (liquid extraction, solid-phase extraction (SPE), dispersive SPE (DSPE), microextraction procedures, matrix solid-phase dispersion (MSPD) and supercritical fluid extraction (SFE) considering low concentration levels of pesticide in baby food resulting from European Union (EU) legislation [11].

The present work reports a GC-TSD method for the determination of OPPs presence in baby food samples purchased from local markets in Constanta, Romania.

\section{Experimental}

Pesticide-grade acetone, n-hexane, izoooctane and anhydrous sodium sulfate were obtained from Merck (Darmstadt, Germany). Pesticide standards of dichlorvos, ethopropos, parathion-methyl, chlorpyrifos, prothiofos, guthion, o,o,o triethyl, thionazin, sulfotep, phorate, disulfoton, parathionethyl, ethion, famphur, dimethoate, diazinon, 
fenchlorphos, malathion, parathion, pirimiphosethyl, methidathion, azinphos were purchased from International Atomic Energy Agency, Monaco laboratory.

A mixed standard solution was prepared from the stock solutions. A series of calibration standards were prepared by diluting $10 \mathrm{mg} / \mathrm{L}$ of the mixed standard solution to produce final concentrations.

Florisil, obtained from Fluka (Switzerland) was assayed for preconcentration step and was activated $12 \mathrm{~h}$ at $130^{\circ} \mathrm{C}$ before use. Anhydrous sodium sulphate was activated at $200^{\circ} \mathrm{C}$ for $2 \mathrm{~h}$ before use.

\subsection{Samples}

Different baby-food samples were purchased from the local market. The different product categories were a fruit-based, a vegetable-based, a meat-vegetable based and fish-vegetable based purée packed in a glass-jar, cereals-based product and biscuits packed in cardboard box. The sample jars and cardboard box were stored unopened at $+4^{\circ} \mathrm{C}$ before the analysis.

\subsection{Sample extraction and clean-up}

$8 \mathrm{~g}$ of each baby-food sample was placed into a homogenizer jar and mixed with anhydrous sodium sulphate in an amount three times greater than the weight sample. The homogenised sample was inserted in a cellulose cartridge (33 x $94 \mathrm{~mm}$ ) which was preliminary cleaned with hexane for $8 \mathrm{~h}$. Then the internal standard was added $(10 \mu \mathrm{L}$ of $2,4,5$, trichlorobiphenile $10 \mathrm{ng} / \mu \mathrm{L})$. The Soxhlet extraction takes $8 \pm 0.5 \mathrm{~h}$ with hexane $(250 \pm 10 \mathrm{~mL})$ as solvent.

The extracts were evaporated under vacuum using a rotary evaporator at $30 \pm 5^{\circ} \mathrm{C}$, with low speed, until $15 \pm 2 \mathrm{~mL}$ volume. Then the concentrated extract was purified by column chromatography. A homemade glass column containing a piece of glass wool on a glass frit was filled with $5 \mathrm{~g}$ of activated Florisil and $1 \mathrm{~g}$ of anhydrous sodium sulfate on the top. The pesticide residues were eluted with hexane: dichlormethane (3:1) mixture and the eluate was collected in a conical evaporating flask. The sorbent was not allowed to dry during the conditioning and sample loading steps. The eluate was finally concentrated in a Kuderna-Danish concentrator to 1 $\pm 0,2 \mathrm{~mL}$. The final extract was kept at $+4^{\circ} \mathrm{C}$ before the analysis.

The internal standard method was used and the basis for internal standard selection was the absence of the compound chosen as internal standard.

\subsection{Instruments}

A Varian gas chromatograph (model 520) equipped with an thermoionic specified detector (TSD) and a fused-silica capillary column $29,6 \mathrm{~m} \mathrm{~L}$ x $0,32 \mathrm{~mm}$ i.d. $\mathrm{x} 0,25 \mu \mathrm{m}$ film thickness were used for pesticides analysis. Operating conditions were as follows: initial temperature $50^{\circ} \mathrm{C}(2 \mathrm{~min})$, increased at a rate of $25^{\circ} \mathrm{C} / \mathrm{min}$ to $300^{\circ} \mathrm{C}$ and finally held for 8 $\mathrm{min}$; injector temperature: $250^{\circ} \mathrm{C}$; carrier gas: $\mathrm{He}$; column flow-rate: $1.86 \mathrm{~mL} / \mathrm{min}$; detector temperature: $300^{\circ} \mathrm{C}$; operation mode: split (electronic pressure control); split/splitless inlet vent - $17.14 \mathrm{~mL} / \mathrm{min}$; purge time on: $2.5 \mathrm{~min}$; purge time off: $7 \mathrm{~min}$; injection volume: $1 \mu \mathrm{L}$.

In Table 1 were presented the retention times for the analysed pesticides.

Table 1. Retention times of studied pesticides

\begin{tabular}{|c|c|}
\hline OPPs & Retention time (min) \\
\hline o,o,o Triethyl & 6.171 \\
\hline Dichlorvos & 6.683 \\
\hline Thionazin & 8.665 \\
\hline Ethopropos & 8.863 \\
\hline Sulfotep & 9.051 \\
\hline Phorate & 9.261 \\
\hline Dimethoate & 9.553 \\
\hline Diazinon & 9.865 \\
\hline Disulfoton & 10.152 \\
\hline Parathion-methyl & 10.887 \\
\hline Fenchlorphos & 11.055 \\
\hline Malathion & 11.422 \\
\hline Chlorpyrifos & 11.620 \\
\hline Parathion & 11.784 \\
\hline Parathion-ethyl & 11.805 \\
\hline Pirimiphos-ethyl & 11.990 \\
\hline Methidathion & 13.092 \\
\hline Prothiofos & 13.780 \\
\hline Ethion & 15.089 \\
\hline Famphur & 15.769 \\
\hline Azinphos & 18.864 \\
\hline Guthion & 18.880 \\
\hline
\end{tabular}


The typical chromatogram of standards is shown

in Fig. 1.

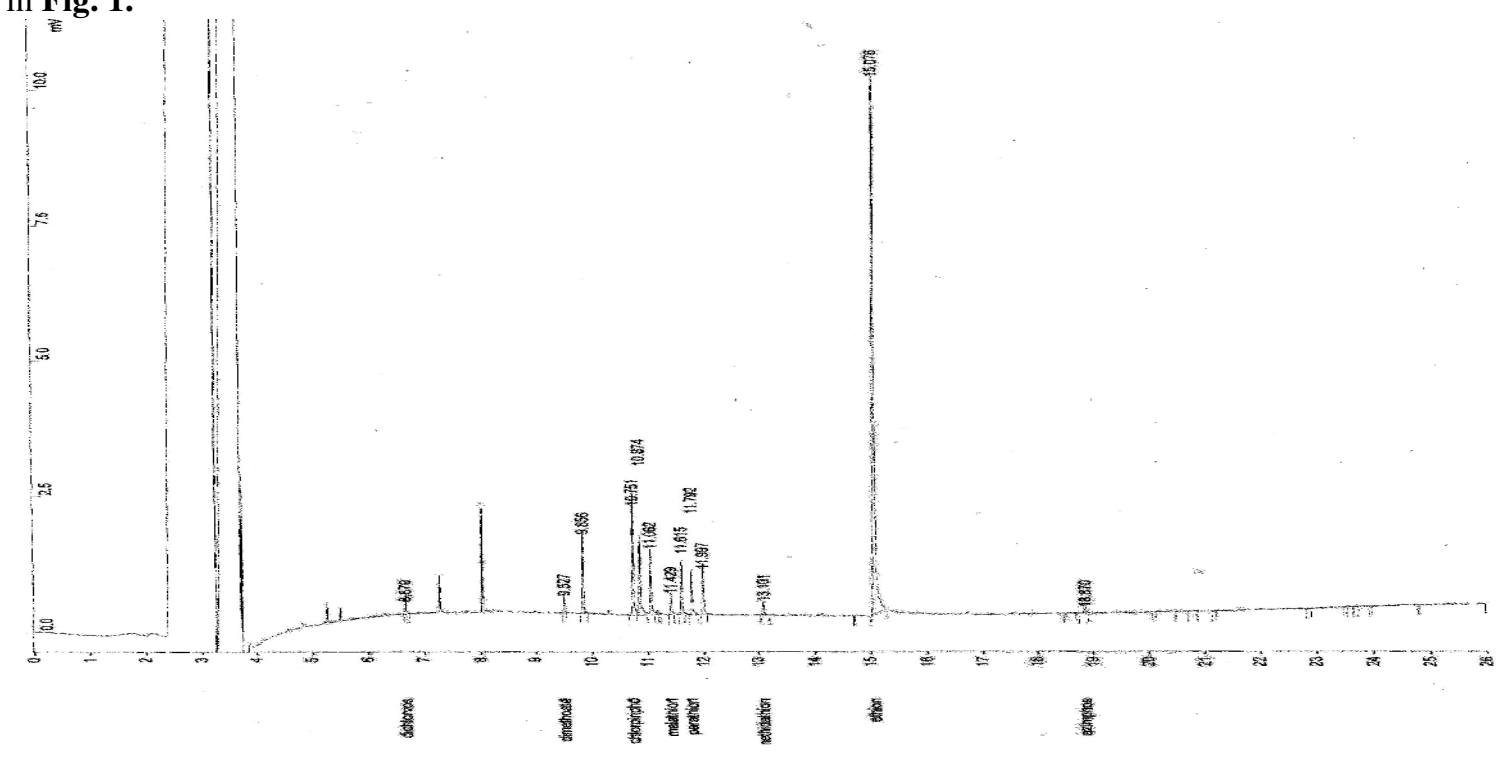

Fig. 1. The chromatogram of OPPs standards

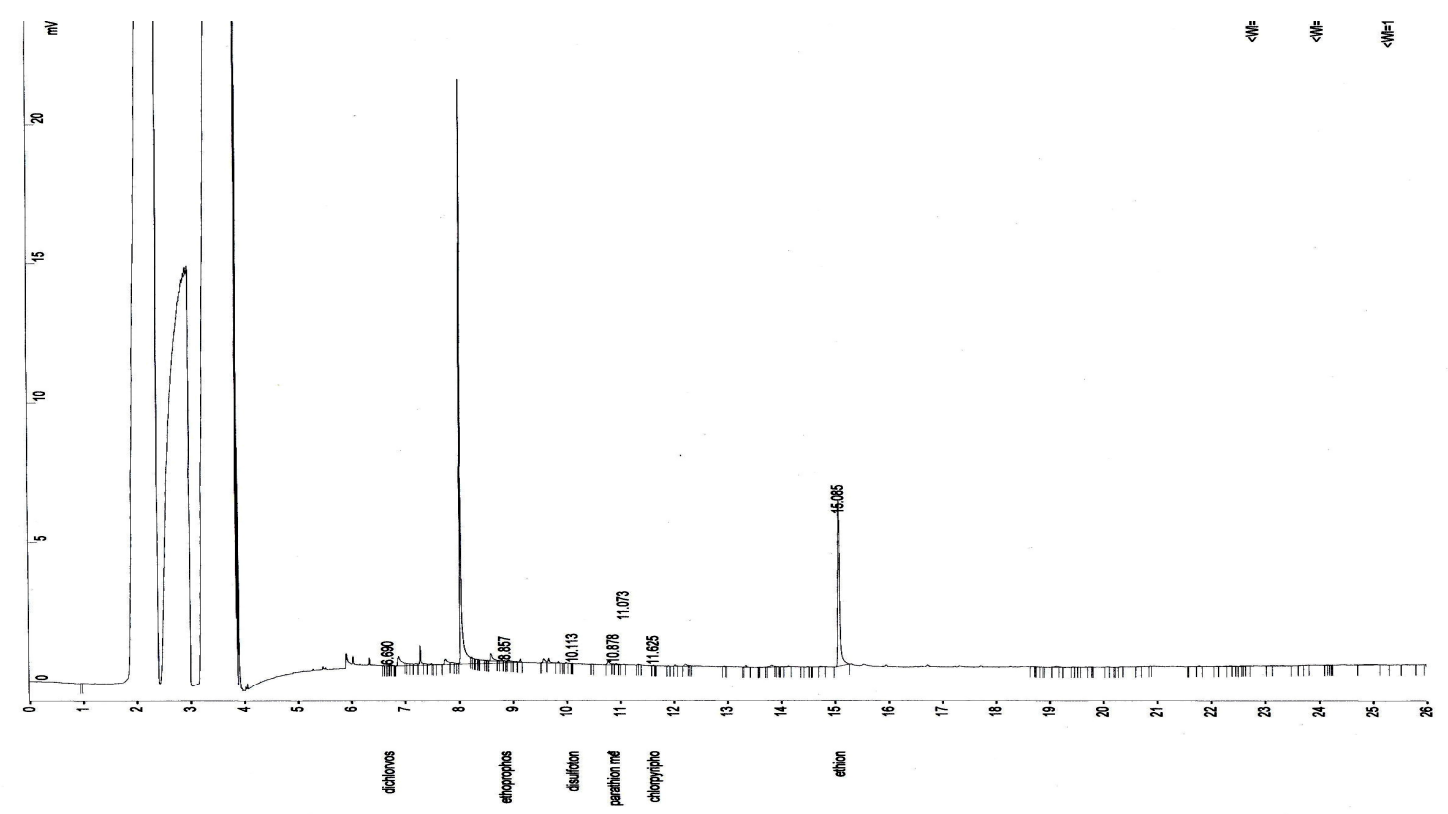

Fig. 2. Chromatogram of a fruits purée sample 


\section{Results and Discussions}

The proposed method was used to determine twentytwo OPPs in baby food samples the representative chromatogram obtained for purée based on fruits are shown in Fig. 2.

The values of pesticide residues concentrations are presented in Tables 2-4.

Table 2. Concentrations of organophosphorus pesticides in vegetable and fruit purée

\begin{tabular}{|c|c|c|}
\hline OPPs & $\begin{array}{c}\text { vegetable based } \\
\text { purée (mg/kg) }\end{array}$ & $\begin{array}{c}\text { fruit based } \\
\text { purée }(\mathrm{mg} / \mathrm{kg})\end{array}$ \\
\hline Dichlorvos & $<$ LOD & $<$ LOD \\
\hline Ethopropos & $<$ LOD & $<$ LOD \\
\hline $\begin{array}{l}\text { Parathion- } \\
\text { methyl }\end{array}$ & $<\mathrm{LOD}$ & $<\mathrm{LOD}$ \\
\hline Chlorpyrifos & $<\mathrm{LOD}$ & $<\mathrm{LOD}$ \\
\hline Prothiofos & $<\mathrm{LOD}$ & $<$ LOD \\
\hline Guthion & $<\mathrm{LOD}$ & $<$ LOD \\
\hline o,o,o Triethyl & 0.0005 & 0.0028 \\
\hline Thionazin & $<\mathrm{LOD}$ & $<\mathrm{LOD}$ \\
\hline Sulfotep & $<\mathrm{LOD}$ & $<$ LOD \\
\hline Phorate & $<\mathrm{LOD}$ & $<$ LOD \\
\hline Disulfoton & 0.0005 & 0.0001 \\
\hline $\begin{array}{l}\text { Parathion- } \\
\text { ethyl }\end{array}$ & $<\mathrm{LOD}$ & $<\mathrm{LOD}$ \\
\hline Ethion & $<\mathrm{LOD}$ & $<\mathrm{LOD}$ \\
\hline Famphur & $<\mathrm{LOD}$ & $<$ LOD \\
\hline Dimethoate & 0.0284 & 0.0082 \\
\hline Diazinon & 0.0069 & 0.0119 \\
\hline Fenchlorphos & $<$ LOD & 0.0132 \\
\hline Malathion & $<$ LOD & $<$ LOD \\
\hline Parathion & $<\mathrm{LOD}$ & $<\mathrm{LOD}$ \\
\hline $\begin{array}{l}\text { Pirimiphos- } \\
\text { ethyl }\end{array}$ & $<\mathrm{LOD}$ & 0.0156 \\
\hline Methidathion & $<\mathrm{LOD}$ & $<\mathrm{LOD}$ \\
\hline Azinphos & $<\mathrm{LOD}$ & $<\mathrm{LOD}$ \\
\hline
\end{tabular}

LOD - detection limit

Recent federal regulations restricting the use of some organophosphorus pesticides may have reduced the use of high-hazard pesticides.

Malathion was under detection limit, except one sample (see table 3 ), but this value is comparable with those encountered by $\mathrm{Lu}$ in processed food for babyes [12].

In 1999 the EU was introduced legislation (1999/39/EC) limits of all pesticides residues to a maximum of $0.01 \mathrm{mg} / \mathrm{Kg}$ potential found in processed cereal-based baby food [13].

Table 3. Concentrations of organophosphorus pesticides in meat-vegetable and fish-vegetable purée

\begin{tabular}{|c|c|c|}
\hline OPPs & $\begin{array}{c}\text { meat-vegetable } \\
\text { based purée } \\
\text { (mg/kg) }\end{array}$ & $\begin{array}{c}\text { fish-vegetable } \\
\text { based purée } \\
\text { (mg/kg) }\end{array}$ \\
\hline Dichlorvos & $<\mathrm{LOD}$ & 0.0031 \\
\hline Ethopropos & 0.0091 & $<\mathrm{LOD}$ \\
\hline $\begin{array}{l}\text { Parathion- } \\
\text { methyl }\end{array}$ & $<\mathrm{LOD}$ & $<\mathrm{LOD}$ \\
\hline Chlorpyrifos & $<\mathrm{LOD}$ & $<\mathrm{LOD}$ \\
\hline Prothiofos & 0.0113 & $<\mathrm{LOD}$ \\
\hline Guthion & 0.0085 & $<\mathrm{LOD}$ \\
\hline o,o,o Triethyl & 0.0066 & 0.0013 \\
\hline Thionazin & $<\mathrm{LOD}$ & $<\mathrm{LOD}$ \\
\hline Sulfotep & 0.0006 & $<\mathrm{LOD}$ \\
\hline Phorate & $<\mathrm{LOD}$ & $<\mathrm{LOD}$ \\
\hline Disulfoton & $<\mathrm{LOD}$ & $<\mathrm{LOD}$ \\
\hline $\begin{array}{l}\text { Parathion- } \\
\text { ethyl }\end{array}$ & $<\mathrm{LOD}$ & $<\mathrm{LOD}$ \\
\hline Ethion & $<\mathrm{LOD}$ & $<\mathrm{LOD}$ \\
\hline Famphur & 0.0006 & $<\mathrm{LOD}$ \\
\hline Dimethoate & 0.0295 & 0.0048 \\
\hline Diazinon & 0.0567 & 0.0014 \\
\hline Fenchlorphos & 0.0644 & $<\mathrm{LOD}$ \\
\hline Malathion & 0.1027 & $<\mathrm{LOD}$ \\
\hline Parathion & $<\mathrm{LOD}$ & $<\mathrm{LOD}$ \\
\hline $\begin{array}{l}\text { Pirimiphos- } \\
\text { ethyl }\end{array}$ & $<\mathrm{LOD}$ & $<\mathrm{LOD}$ \\
\hline Methidathion & $<\mathrm{LOD}$ & $<\mathrm{LOD}$ \\
\hline Azinphos & $<\mathrm{LOD}$ & $<\mathrm{LOD}$ \\
\hline
\end{tabular}

LOD - detection limit

From Table 4 it can be observed that some analyzed phosphorus pesticides are above these maximum limits (parathion-methyl $0.0131 \mathrm{mg} / \mathrm{Kg}$; prothiofos $0.0364 \mathrm{mg} / \mathrm{Kg}$; dimethoate $0.046 \mathrm{mg} / \mathrm{Kg}$; diazinon $0.1096 \mathrm{mg} / \mathrm{Kg} ;$ fenchlorphos 0.1903 $\mathrm{mg} / \mathrm{Kg}$; pirimiphos-ethyl $0.0705 \mathrm{mg} / \mathrm{Kg}$ ).

The EU directive for cereal based baby food [14] focuses on pesticides control or metabolites 
with a maximum daily accepted dose by 0.0005 $\mathrm{mg} / \mathrm{kg}$ body.

Table 4. Concentrations of organophosphorus pesticides in cereal based baby food and biscuits

\begin{tabular}{|l|c|c|}
\hline \multicolumn{1}{|c|}{ OPPs } & $\begin{array}{c}\text { Cereal based } \\
\text { baby food }\end{array}$ & Biscuits \\
\hline Dichlorvos & $<$ LOD & $<$ LOD \\
\hline Ethopropos & $<$ LOD & $<$ LOD \\
\hline $\begin{array}{l}\text { Parathion- } \\
\text { methyl }\end{array}$ & 0.0131 & $<$ LOD \\
\hline Chlorpyrifos & $<$ LOD & $<$ LOD \\
\hline Prothiofos & 0.0364 & $<$ LOD \\
\hline Guthion & $<$ LOD & $<$ LOD \\
\hline o,o,o Triethyl & 0.0050 & 0.0003 \\
\hline Thionazin & $<$ LOD & $<$ LOD \\
\hline Sulfotep & 0.0013 & 0.00006 \\
\hline Phorate & $<$ LOD & $<$ LOD \\
\hline Disulfoton & $<$ LOD & 0.0001 \\
\hline Parathion-ethyl & $<$ LOD & 0.0001 \\
\hline Ethion & $<$ LOD & $<$ LOD \\
\hline Famphur & $<$ LOD & $<$ LOD \\
\hline Dimethoate & 0.046 & 0.0016 \\
\hline Diazinon & 0.1096 & 0.0011 \\
\hline Fenchlorphos & 0.1903 & $<$ LOD \\
\hline Malathion & $<$ LOD & $<$ LOD \\
\hline Parathion & $<$ LOD & $<$ LOD \\
\hline $\begin{array}{l}\text { Pirimiphos- } \\
\text { ethyl }\end{array}$ & 0.0705 & 0.0004 \\
\hline Methidathion & $<$ LOD & $<$ LOD \\
\hline Azinphos & $<$ LOD & $<$ LOD \\
\hline LOD $--4 t e c t i n$ & \\
\hline
\end{tabular}

LOD - detection limit

\section{Conclusions}

The obtained results indicate that some of the detected pesticides exceed the allowed maximum residue limits showing a very low contamination level with organophosphorus pesticides of investigated samples.

Chlorpyrifos, thionazin, phorate, ethion, parathion, methidathion and azinphos were under detection limit for all studied samples.

Further study is needed to understand the monitoring system and what people can do to minimize their exposure to pesticides.

\section{References}

* E-mail address: sdobrinas@ univ-ovidius.ro

[1]. C.L. Curl, R.A. Fenske and K. Elgethun, Environmental Health Perspectives, 11(3), 377-382 (2003).

[2]. D. M Roberts and C. K Aaron, BMJ, 334, 629-634, (2007) doi: 10.1136/bmj.39134.566979.BE

[3]. K. Buonasera, G. D'Orazio, S. Fanali, P. Dugo and L. Mondello, Journal of Chromatography A, 1216, 3970-3976 (2009)

[4]. C. Merus, C. Corradini, A. Cavazza, C. Borrome and P. Salvadeo, Food Chemistry, 120, 615-620 (2010) [5]. EC Council Directive 2006/125/EC of 5 December 2006 on processed cereal-based foods and baby foods for infants and young children. In: Official Journal of the European Union, Vol. L339, European Community, Brussels, 16-35, (2006).

[6]. P. Georgakopoulos, R. Zachari, M. Mataragas, P. Athanasopoulos, E. H. Drosinos and P. N. Skandamis, Food Chemistry, 128, 536-542, (2011)

[7]. C. C. Leandro, P. Hancock, R. J. Fussell and B. J. Keely, Journal of Chromatography A, 1103 (1), 94-101 (2006)

[8]. P. Sandra, B. Tienpont and F. David, Journal of Chromatography A, 1000, 299-309 (2003)

[9]. A. Hercegová, M. Dömötörová, E. Matisová, M. Kirchner, R. Otrekal and V. Štefuca, Journal of Chromatography A, 1084 (1-2), 46-53 (2005)

[10]. C. C. Leandro, R. J. Fussell and B. J. Keely, Journal of Chromatography A, 1085 (2), 207-212 (2005)

[11]. A. Hercegova, M. Domotorova and E. Matisova, Journal of Chromatography A, 1153, 54-73, (2007)

[12]. C. Lu, G.Kedan, J. Fisker-Andersen and J.C. Kissel, R.A. Fenske, Environmental Research, 96, 283289, (2004)

[13].***Commission Directive 1999/39/EC of 6 May 1999 amending Directive96/5/EC on processed cerealbased foods and baby foods for infants and young children, Off. J. Eur. Commun, vol. L124, (1999)

[14].*** Commission Directive 2003/13/EC of 10 February 2003 amending Directive96/5/EC on processed cereal-based foods and baby foods for infants and young children, Off. J. Eur. Commun, vol. L41, (2003).

Submitted: March 15 2012 Accepted in revised form: April $26^{\text {th }} 2012$ 